\title{
Dielectric Relaxation Studies of 2-Butoxyethanol with Aniline and Substituted Anilines Using Time Domain Reflectometry
}

\author{
P. Jeevanandham, ${ }^{1}$ S. Kumar, ${ }^{2}$ P. Periyasamy, ${ }^{2}$ and A. C. Kumbharkhane ${ }^{3}$ \\ ${ }^{1}$ Dr.Nallini Institute of Engineering and Technology, Dharapuram, Tamil Nadu 638673, India \\ ${ }^{2}$ Department of Physics, Annamalai University, Annamalai Nagar, Tamil Nadu 608002, India \\ ${ }^{3}$ School of Physics, S.R.T.M. University, Nanded, Maharashtra 431606, India \\ Correspondence should be addressed to P. Jeevanandham; jeeva.phys86@gmail.com
}

Received 19 June 2013; Revised 17 October 2013; Accepted 25 October 2013; Published 18 February 2014

Academic Editor: Jyh-Ping Hsu

Copyright (C) 2014 P. Jeevanandham et al. This is an open access article distributed under the Creative Commons Attribution License, which permits unrestricted use, distribution, and reproduction in any medium, provided the original work is properly cited.

\begin{abstract}
The complex dielectric spectra of 2-butoxyethanol with aniline and substituted anilines like aniline, $o$-chloroaniline, $m$ chloroaniline, $o$-anisidine and $m$-anisidine binary mixtures in the composition of different volumes of percent $(0 \%, 25 \%, 50 \%$, $75 \%$, and $100 \%$ ) have been measured as a function of frequency between $10 \mathrm{MHz}$ and $30 \mathrm{GHz}$ at $298.15 \mathrm{~K}$. The dielectric parameters like static dielectric constant $\left(\varepsilon_{0}\right)$ and relaxation time $(\tau)$ have been obtained by using least square fit method. By using these parameters $\left(\varepsilon_{0}, \tau\right)$, effective Kirkwood correlation factor $\left(g^{\text {eff }}\right)$, corrective Kirkwood correlation factor $\left(g_{f}\right)$, Bruggeman factor $\left(f_{B}\right)$, excess dielectric constant $\left(\varepsilon^{E}\right)$, and excess inverse relaxation time $(1 / \tau)^{E}$ values are calculated and discussed to yield information on the dipolar alignment and molecular rotation of the binary liquid mixtures. From all the derived dielectric parameters, molecular interactions are interpreted through hydrogen bonding.
\end{abstract}

\section{Introduction}

Time domain reflectometry technique is the powerful tool to identify the inter- and intramolecular rotations of the liquid and liquid mixtures. Dielectric studies on mixtures of polar liquids either in the pure state or in the inert solvents have been a subject of interest because they provide useful information regarding molecular complex formation in solution [1]. A significance of the intermolecular interactions in the dynamics of molecules, as revealed in dielectric relaxation spectroscopy, is one of the most important and still open problems of molecular physics of the liquid state [2]. Anilines are the prototypical aromatic amine. Being a precursor to many industrial chemicals, their main use is in the manufacture of precursors to polyurethane. 2-Alkoxyethanols are the combinations of ether, alcohol, and hydrocarbon chain in one molecule, providing versatile solvency characteristics with both polar and nonpolar properties [3]. In the series of 2-alkoxyethanols, ethylene glycol monobutyl ether (2butoxyethanol) was selected for the present investigation, because 2-BE is a commercial liquid that is mainly used for the cleaning purpose. The dipole moment value of $2-\mathrm{BE}$ is 2.08 Debye and is having high $\mathrm{pKa}$ for $\mathrm{OH}$ group. Rana et al. [4] carried out the dielectric relaxation study of 1-propanol with 2-chloroaniline and 3-chloroanilines over the entire range of concentration at frequency ranging from $10 \mathrm{MHz}$ to $10 \mathrm{GHz}$ using time domain reflectometry (TDR) technique at four different temperatures. They found strong intermolecular association between the anilines in 1-propanol. Krishna and Sastry [5] studied the dielectric and thermodynamic properties of aniline in isopropyl alcohol at five different temperatures. So many attempts have been made in the study of dielectric properties of aniline and alcohols [6-11]. But no attempt has been taken for the dielectric study of anilines like aniline, $o$-chloroaniline $(o$-CA), $m$-chloroaniline $(m$-CA), $o$ anisidine $(o-\mathrm{A})$, and $m$-anisidine ( $m$-A) with 2-butoxyethanol (2-BE). The complex dielectric permittivity in the frequency range from $10 \mathrm{MHz}$ to $30 \mathrm{GHz}$ has been determined by using Tektronix Digital Serial Analyzer. The aim of our present investigation is to describe the molecular association 
of anilines with 2-butoxyethanol binary mixtures through dielectric properties. It has been measured by using different dielectric parameters like static dielectric constant, relaxation time, Bruggeman factor, Kirkwood correlation factors, excess dielectric permittivity, and excess inverse relaxation time at $298.15 \mathrm{~K}$.

\section{Material and Methods}

2.1. Chemicals. All compounds used in this work were supplied by Loba (purity $\gg 99 \%$ ) chemicals and were used as such without further purification. The purity of chemicals was checked by comparing their densities with literature values. The binary mixtures were prepared using airtight stoppered bottles (to avoid evaporation) and the mixtures were prepared at an interval of $25 \%$ anilines.

2.2. Measurements. The dielectric spectra have been obtained by the time domain reflectometry (TDR) technique. The Tektronix model no. DSA8200 Digital Serial Analyzer sampling mainframe along with the sampling module 80E08 has been used for the measurement. A repetitive fast rising voltage pulse with 18 ps incident rise time was fed through coaxial line system of $50 \Omega$ impedance. Sampling oscilloscope monitors changes in step pulse after reflection from the end of line. Reflected pulse without sample $R_{1}(t)$ and with sample $R_{x}(t)$ were recorded in the time window of $2 \mathrm{~ns}$ and digitized in 2000 points. The Fourier transformation of the pulses and data analysis were done earlier to determine complex permittivity spectra $\varepsilon^{*}(\omega)$ using nonlinear least squares fit method [12-14]. The experimental values of $\varepsilon^{*}(\omega)$ are fitted with Debye equation [15-17]:

$$
\varepsilon^{*}(\omega)=\varepsilon_{\infty}+\frac{\left(\varepsilon_{0}-\varepsilon_{\infty}\right)}{1+j \omega \tau},
$$

where $\left(\varepsilon_{0}\right),\left(\varepsilon_{\infty}\right)$, and $(\tau)$ are fitting parameters. In $(1),\left(\varepsilon_{0}\right)$ is the static permittivity, $(\tau)$ is the relaxation time, and $\left(\varepsilon_{\infty}\right)$ is the permittivity at high frequency.

\section{Result and Discussion}

Figures 1(a), 1(b), 2(a) and 2(b) show the complex permittivity (dielectric permittivity and loss) spectra of aniline and $m$ anisidine with 2-butoxyethanol binary mixtures at $298.15 \mathrm{~K}$. In the case of aniline, $o$-chloroaniline, and $o$-anisidine with 2-butoxyethanol systems, the position of the peak in the plot of dielectric loss versus $\log F$ shifts towards higher frequency with increasing volume percent of anilines. But in $\mathrm{m}$ chloroaniline and $m$-anisidine with 2-butoxyethanol systems the position of the peak in the plot of dielectric loss versus $\log F$ shifts towards lower frequency with increasing volume percent of $m$-chloroaniline and $m$-anisidine. This shows that the relaxation time decreases with the increasing volume percent of aniline, $o$-chloroaniline, and $o$-anisidine systems and the relaxation time increases for the volume percent of $m$-chloroaniline and $m$-anisidine systems [18]. The molecular interaction taking place in the binary liquid mixtures can be explained by the measured values of static dielectric constant $\left(\varepsilon_{0}\right)$ and relaxation time $(\tau)$. A perusal Table 1 contains the experimental values of static dielectric constant and relaxation time of anilines with 2-butoxyethanol binary systems at $298.15 \mathrm{~K}$. The static dielectric constant values decrease for aniline, $o$-chloroaniline, $o$-anisidine, and $m$-anisidine systems and increase for $m$-chloroaniline system. The nonlinearity behaviour of static dielectric constant values in each studied system can be attributed to the appearance of aggregates in solutions. The dielectric constant at an optical frequency $\left(\varepsilon_{\infty}\right)$ values increases with increasing concentration of solutes (anilines) for all the studied systems. The relaxation time depends critically on the nature of functional groups and volume of molecule. Functional groups that are able to form hydrogen bonding have a strong influence on relaxation time [19]. Aniline has the free $\mathrm{NH}_{2}$ group in the benzene ring. But in the case of substituted anilines (o-chloroaniline, $\mathrm{m}$ chloroaniline, $o$-anisidine, and $m$-anisidine) the functional group is added to the isomers of benzene ring with respective $\mathrm{NH}_{2}$ group. The relaxation times of aniline, $o$-chloroaniline, $m$-chloroaniline, $o$-anisidine, and $m$-anisidine at $298.15 \mathrm{~K}$ are 16.20 ps, 24.22 ps, 50.89 ps, 9.89 ps, and 124.27 ps, respectively. This shows that there is a systematic increase in relaxation time, when chlorine and methoxy groups shift from $o$ to $m$-position with respect to the amino group. From the studied systems more relaxation effects appear in the form of Maxwell-Wagner-Sillars relaxation peaks. Similar behaviour was observed by Srivastava and Vij [20] in their study of three chloroanilines in dilute benzene solution. A regular variation in relaxation time values may be due to the change in the molecular volume or change in the effective length of the dipole involved in the orientation process.

The structural information about the liquids from the dielectric relaxation parameter may be obtained by using the Kirkwood correlation parameter " $g$ " [21]. This parameter is useful for obtaining information regarding orientation of electric dipoles in polar liquids. The structural information on the interacting species is obtained by corrective correlation factor $\left(g_{f}\right)$. The $\left(g_{f}\right)$ values are deviated from unity, indicating strong intermolecular interactions between components of the studied systems $[22,23]$. This significant deviation from unity in the $\left(g_{f}\right)$ values of the studied systems confirms that the effective dipoles in the mixture will be less than the corresponding average value in pure liquids and the clustering due to dipole-dipole interaction between the two hetero molecules. Modified forms of corrective correlation factor have been used to study the orientation of electric dipoles in binary mixture of anilines with 2-BE named as the effective Kirkwood correlation factor $\left(g^{\text {eff }}\right)$ [24-26].

The effective Kirkwood correlation factor $\left(g^{\text {eff }}\right)$ that is calculated using (3) is given in Table 2 at $298.15 \mathrm{~K}$. The $g^{\text {eff }}$ values will change from $g_{1}$ to $g_{2}$ as concentration of molecule 2 will increase from $0 \%$ to $100 \%$. The information on dipoledipole correlation in associating polar liquid can be derived from effective correlation factor [22]. If the $g^{\text {eff }}$ values are greater than unity which indicates the parallel orientation of dipoles and if less than unity which indicates the antiparallel orientation of dipoles. In pure state the $g^{\text {eff }}$ value of 2butoxyethanol (1.939) is greater than unity, indicating parallel 


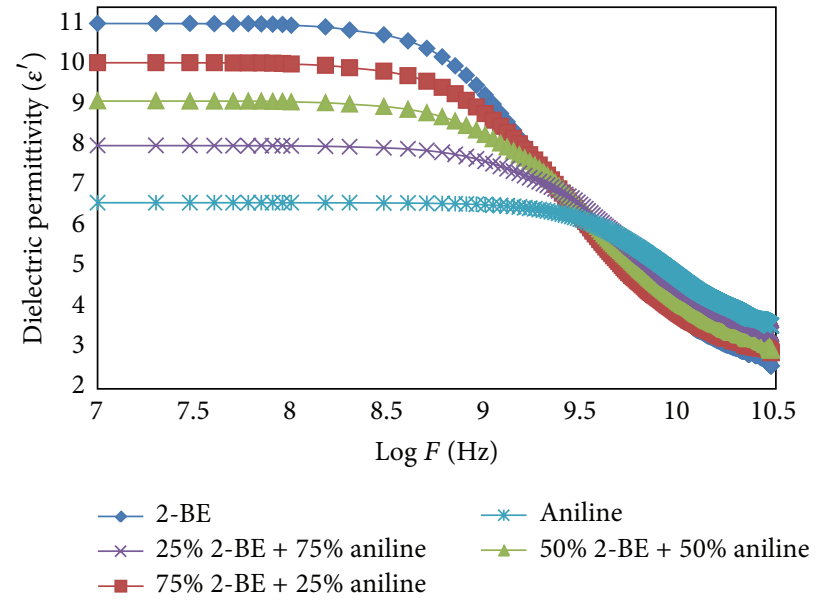

(a)

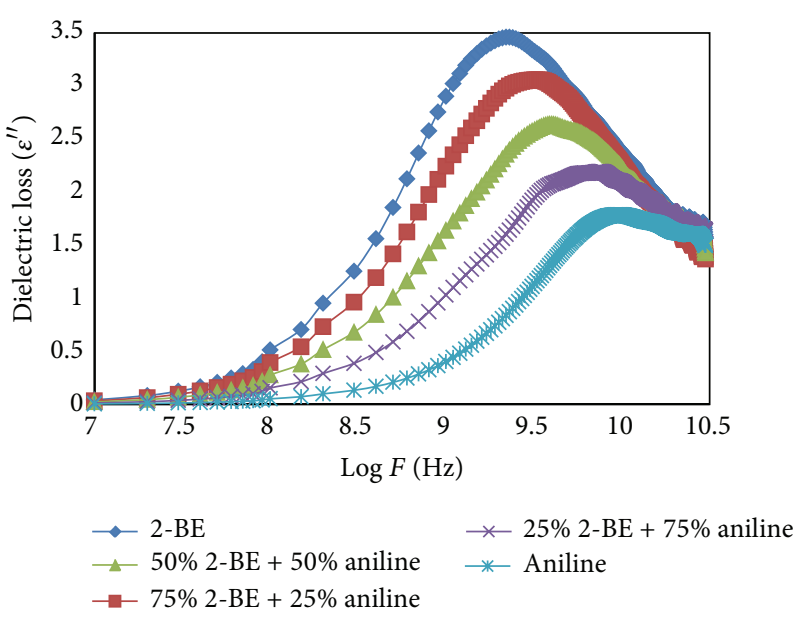

(b)

Figure 1: (a) The dielectric permittivity spectra of aniline + 2-butoxyethanol binary mixtures. (b) The dielectric loss spectra of aniline +2 butoxyethanol binary mixtures.

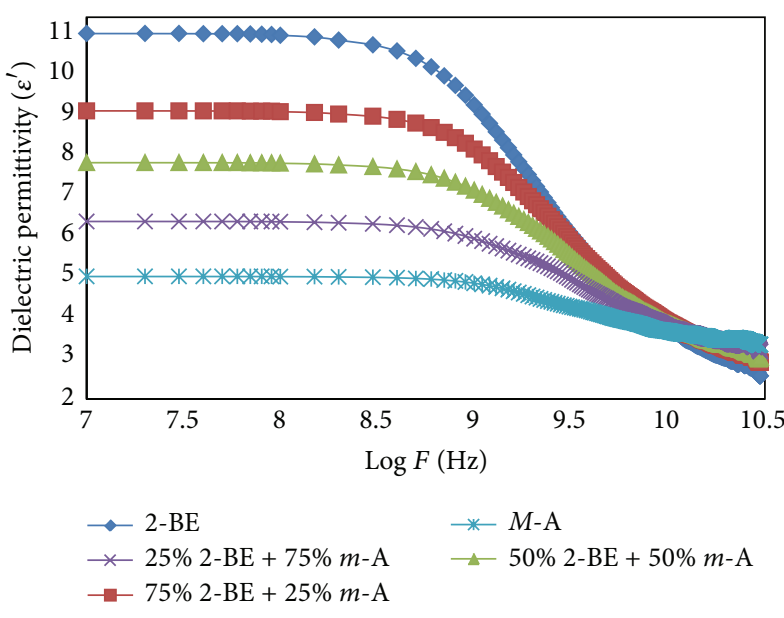

(a)

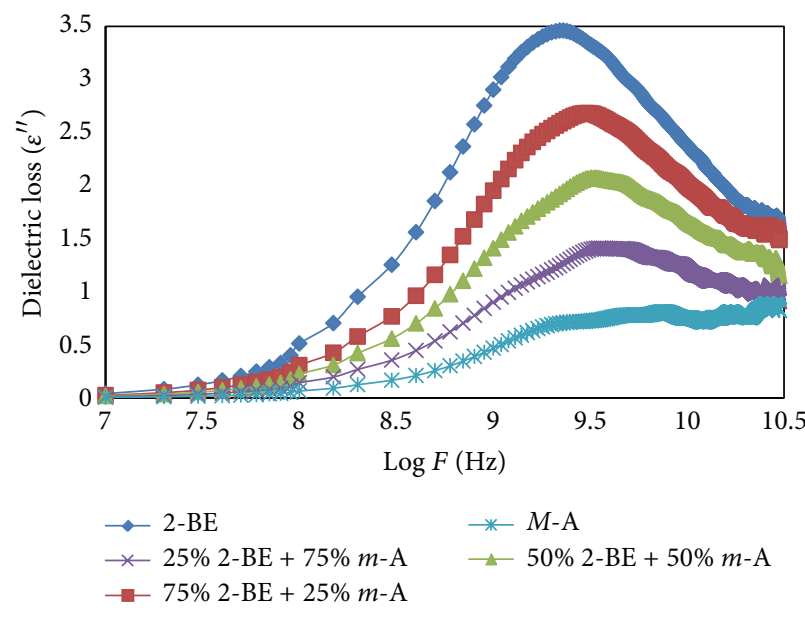

(b)

Figure 2: (a) The dielectric permittivity spectra of $m$-anisidine + 2-butoxyethanol binary mixtures. (b) The dielectric loss spectra of $m$ anisidine +2 -butoxyethanol binary mixtures.

orientation of electric dipoles. The $g^{\text {eff }}$ values of pure anilines like aniline (0.898), $o$-chloroaniline (0.742), $m$-chloroaniline (0.632), and $o$-anisidine (0.568) are less than unity, indicating antiparallel orientation of electric dipoles, in the case of $m$ anisidine the $g^{\text {eff }}$ value is greater than unity (1.168). As the volume $\%$ of solute (anilines) increases, the $g^{\text {eff }}$ values are decreasing. It is interesting to note that the $g^{\text {eff }}$ values are more deviated from unity and are found to be larger. This confirms the greater ability of 2-BE to form hydrogen bonds with aniline molecules.

The Bruggeman factor which is the ratio of theoretical values of static dielectric constant computed from Bruggeman mixture formula and practically obtained values has been obtained (Figure 3)[23]. A linear relationship is expected from the Bruggeman factor values, which gives a straight line when $f_{B}$ plotted against $\phi_{2}$. However here the experimental values of $\left(f_{B}\right)$ were found to deviate from the linear relations. The nonlinear relation of $\left(f_{B}\right) 2-$ butoxyethanol with aniline systems suggests an intermolecular interaction taking place in the mixed components. It is assumed that the volume fraction $\left(\phi_{2}\right)$ in the mixture is modified by a factor $[a-(a-1) \phi]$. This modification may be due to the structural rearrangement of solute (anilines) molecule in the mixtures [27]. The values of " $a$ " contain information regarding the change in the orientation of the solute molecules (anilines) in the mixture. The values of " $a$ " are determined from the least square fit method, for all the studied systems. The value of " $a$ " $=1$ corresponds to the ideal Bruggeman mixture formula. The deviation from unity relates to corresponding solute-solute interaction. The values of " $a$ " are 1.514 (aniline), 2.562 (o-CA), $2.843(m-\mathrm{CA}), 3.164$ $(o-A)$, and $0.934(m-A)$, respectively.

The excess properties like excess dielectric constant $\left(\varepsilon^{E}\right)$ and excess inverse relaxation time $(1 / \tau)^{E}$ provide valuable 
TABLE 1: Values of static dielectric constant $\left(\varepsilon_{0}\right)$ and relaxation time $(\tau)$ of aniline +2 -butoxyethanol binary mixtures at $298.15 \mathrm{~K}$.

\begin{tabular}{|c|c|c|c|c|c|}
\hline$\%$ Aniline & Aniline $+2-\mathrm{BE}$ & $o-\mathrm{CA}+2-\mathrm{BE}$ & $m-\mathrm{CA}+2-\mathrm{BE}$ & $o-\mathrm{A}+2-\mathrm{BE}$ & $m-\mathrm{A}+2-\mathrm{BE}$ \\
\hline & \multicolumn{5}{|c|}{ Static dielectric constant $\left(\varepsilon_{0}\right)$} \\
\hline $0 \%$ & $9.99(4)$ & $9.99(4)$ & $09.99(4)$ & $9.99(4)$ & $9.99(4)$ \\
\hline $25 \%$ & $9.09(1)$ & $9.45(5)$ & $10.43(7)$ & $9.37(4)$ & $9.78(1)$ \\
\hline $50 \%$ & $8.30(6)$ & $8.98(7)$ & $11.05(3)$ & $8.02(4)$ & $9.57(1)$ \\
\hline $75 \%$ & $7.48(2)$ & $8.16(3)$ & $11.96(8)$ & $5.94(4)$ & $9.36(3)$ \\
\hline \multirow[t]{2}{*}{$100 \%$} & $6.59(1)$ & $7.78(4)$ & $12.94(6)$ & $4.45(4)$ & $9.21(4)$ \\
\hline & \multicolumn{5}{|c|}{ Dielectric constant at optical frequency $\left(\varepsilon_{\infty}\right)$} \\
\hline $0 \%$ & $1.719(2)$ & $1.719(2)$ & $1.719(2)$ & $1.719(2)$ & $1.719(2)$ \\
\hline $25 \%$ & $2.196(2)$ & $2.299(3)$ & $2.342(1)$ & $2.323(4)$ & $2.325(1)$ \\
\hline $50 \%$ & $2.469(1)$ & $2.364(2)$ & $2.506(4)$ & $2.414(4)$ & $2.421(1)$ \\
\hline $75 \%$ & $2.742(1)$ & $2.512(1)$ & $2.747(3)$ & $2.502(4)$ & $2.635(3)$ \\
\hline \multirow[t]{2}{*}{$100 \%$} & $2.826(1)$ & $2.814(1)$ & $3.043(1)$ & $2.652(4)$ & $2.794(2)$ \\
\hline & \multicolumn{5}{|c|}{ Relaxation time $(\tau)$ ps } \\
\hline $0 \%$ & $47.86(9)$ & $47.86(9)$ & $47.86(9)$ & $47.86(9)$ & $47.86(9)$ \\
\hline $25 \%$ & $40.12(7)$ & $42.54(6)$ & $48.36(9)$ & 38.36 (11) & $63.78(13)$ \\
\hline $50 \%$ & $28.12(4)$ & $37.35(3)$ & $48.89(6)$ & $28.87(6)$ & $89.08(7)$ \\
\hline $75 \%$ & $21.25(6)$ & 30.49 (4) & $49.78(5)$ & $19.38(7)$ & 101.12 (11) \\
\hline $100 \%$ & $16.20(8)$ & $24.22(8)$ & $50.89(7)$ & $10.45(8)$ & $124.27(15)$ \\
\hline
\end{tabular}

The number in bracket represents error in least significant digit of the corresponding value as obtained by the least squares fit method; for example, 9.99 (1) means $9.99 \pm 0.01$.

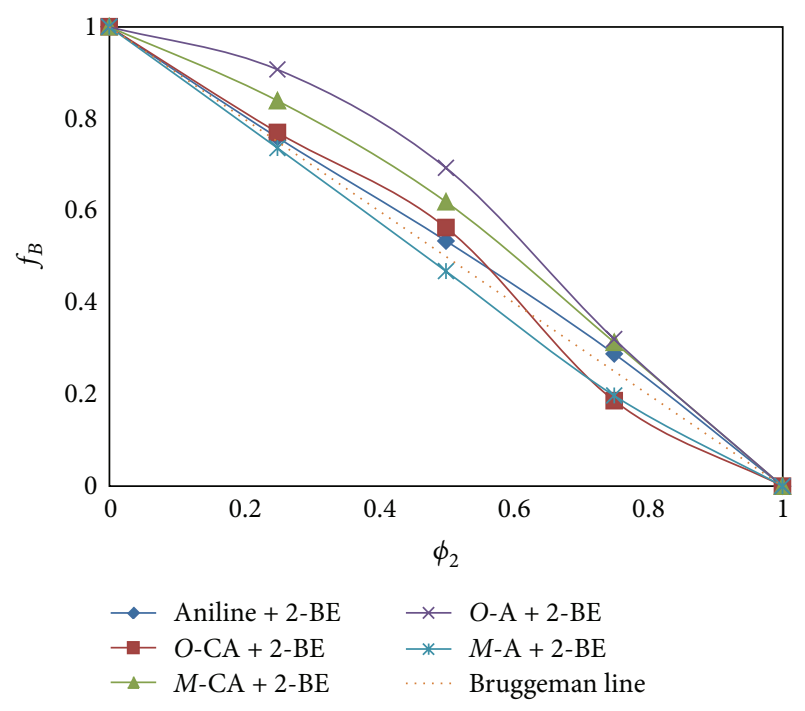

FIGURE 3: Bruggeman factor versus volume fraction of anilines.

information about the formation of multimers in the mixture. The excess permittivity is defined as [28-30]. In an ideal mixture of polar liquids if the molecules are interacting, a nonlinear variation in dielectric constant and relaxation time occurs. This confirms that the intermolecular association is taking place in the system. The excess property related to permittivity and relaxation time provides significant information regarding interaction between the polarpolar liquid mixtures. The values of $\left(\varepsilon^{E}\right)$ are negative for the whole composition for $m$-chloroaniline and $m$-anisidine with 2-butoxyethanol (Table 3 ) systems. The negative values indicate the formation of multimer structures which leads to decrease in the total number of dipoles in the systems. In the case of aniline +2-butoxyethanol system the excess dielectric constant values are initially negative and the volume fraction of aniline that increases the values of $\left(\varepsilon^{E}\right)$ goes to positive. But in the case of $o$-chloroaniline +2 -butoxyethanol system the values of $\left(\varepsilon^{E}\right)$ are positive at the lower volume fraction of anilines and negative at the higher volume fraction of anilines. The $\left(\varepsilon^{E}\right)$ values are positive for the whole composition of $o$ anisidine +2 -butoxyethanol systems. Positive values of $\left(\varepsilon^{E}\right)$ indicate the formation of monomeric, dimeric, or polymeric structures which increase the total number of dipoles in the system.

Excess inverse relaxation time $(1 / \tau)^{E}$ values are negative for all the studied systems except $m$-chloroaniline with 2 butoxyethanol system, which are listed in Table 2. Negative values of $(1 / \tau)^{E}$ indicate the formation of structures rotating slowly which may be probably due to dimeric structure of anilines, that is, the anilines creating a hindering field and hence the effective dipoles rotate slowly due to the formation of hydrogen bonded structures. But in the case of $m$-chloroaniline with 2-butoxyethanol system the excess inverse relaxation time values are positive for the whole composition range. The positive trend of $(1 / \tau)^{E}$ suggests the fast rotation of dipoles in the systems. This may be due to the formation of monomeric structure in this region. The negative trend of $(1 / \tau)^{E}$ suggests that the solute-solvent 
TABLE 2: Values of effective and corrective Kirkwood correlation factor $\left(g^{\text {eff }}, g_{f}\right)$, Bruggeman factor $\left(f_{B}\right)$, excess dielectric constant $\left(\varepsilon^{E}\right)$, and excess inverse relaxation time $(1 / \tau)^{E}$ of anilines with 2-butoxyethanol binary mixtures $298.15 \mathrm{~K}$.

\begin{tabular}{|c|c|c|c|c|c|}
\hline$\phi_{2}$ & $g^{\text {eff }}$ & $g_{f}$ & $f_{B}$ & $\varepsilon^{E}$ & $(1 / \tau)^{E} \mathrm{ps}$ \\
\hline \multicolumn{6}{|c|}{ Aniline +2 -butoxyethanol } \\
\hline 0 & $1.939(1)$ & 1.000 & 1.000 & 0.000 & 0.0000 \\
\hline 0.25 & $1.555(0)$ & 0.818 & 0.759 & -0.051 & -0.0067 \\
\hline 0.5 & $1.284(1)$ & 0.793 & 0.534 & 0.007 & -0.0062 \\
\hline 0.75 & $1.040(3)$ & 0.806 & 0.288 & 0.038 & -0.0043 \\
\hline 1 & $0.898(2)$ & 1.000 & 0.000 & 0.000 & 0.0000 \\
\hline \multicolumn{6}{|c|}{$o$-Chloroaniline +2 -butoxyethanol } \\
\hline 0 & $1.939(1)$ & 1.000 & 1.000 & 0.000 & 0.0000 \\
\hline 0.25 & $1.290(3)$ & 0.789 & 0.770 & 0.014 & -0.0026 \\
\hline 0.5 & $1.164(1)$ & 0.871 & 0.563 & 0.097 & -0.0043 \\
\hline 0.75 & $0.944(1)$ & 0.909 & 0.186 & -0.169 & -0.0037 \\
\hline 1 & $0.742(3)$ & 1.000 & 0.000 & 0.000 & 0.0000 \\
\hline \multicolumn{6}{|c|}{$m$-Chloroaniline +2 -butoxyethanol } \\
\hline 0 & $1.939(1)$ & 1.000 & 1.000 & 0.000 & 0.0000 \\
\hline 0.25 & $1.128(2)$ & 0.802 & 0.839 & -0.297 & 0.0001 \\
\hline 0.5 & $0.920(1)$ & 0.868 & 0.619 & -0.415 & 0.0002 \\
\hline 0.75 & $0.761(3)$ & 0.934 & 0.313 & -0.243 & 0.0001 \\
\hline 1 & $0.632(0)$ & 1.000 & 0.000 & 0.000 & 0.0000 \\
\hline \multicolumn{6}{|c|}{$o$-Anisidine +2 -butoxyethanol } \\
\hline 0 & $1.939(1)$ & 1.000 & 1.000 & 0.000 & 0.0000 \\
\hline 0.25 & $1.419(1)$ & 0.824 & 0.907 & 0.765 & -0.0143 \\
\hline 0.5 & $1.264(3)$ & 0.876 & 0.693 & 0.800 & -0.0246 \\
\hline 0.75 & $0.907(0)$ & 0.844 & 0.320 & 0.105 & -0.0251 \\
\hline 1 & $0.568(1)$ & 1.000 & 0.000 & 0.000 & 0.0000 \\
\hline \multicolumn{6}{|c|}{$m$-Anisidine +2 -butoxyethanol } \\
\hline 0 & $1.939(1)$ & 1.000 & 1.000 & 0.000 & 0.0000 \\
\hline 0.25 & $1.394(3)$ & 0.786 & 0.736 & -0.015 & -0.0020 \\
\hline 0.5 & $1.350(2)$ & 0.849 & 0.468 & -0.030 & -0.0030 \\
\hline 0.75 & $1.230(1)$ & 0.885 & 0.197 & -0.045 & -0.0010 \\
\hline 1 & $1.168(3)$ & 1.000 & 0.000 & 0.000 & 0.0000 \\
\hline
\end{tabular}

The number in bracket represents error in least significant digit of the corresponding value as obtained by the least squares fit method; for example, 1.939 (1) means $1.939 \pm 0.01$.

interaction produces a field such that the effective dipoles rotate slowly. Krishna and MadhuMohan [31] have reported the negative and positive values $(1 / \tau)^{E}$ in $\mathrm{N}$-methylaniline with alcohols.

The excess Helmholtz free energy $\left(\Delta F^{E}\right)$ is a parameter to evaluate the interaction between the components in the mixture through breaking mechanism of hydrogen bond and is expressed [32-35] as

$$
\Delta F^{E}=\Delta F_{0}^{E}+\Delta F_{r r}^{E}+\Delta F_{12}^{E}
$$

where $\left(\Delta F_{0}^{E}\right)$ represents the excess dipolar energy due to long range electrostatic interaction, $\left(\Delta F_{r r}^{E}\right)$ represents the excess dipolar energy due to short range interaction between identical molecules, and $\left(\Delta F_{12}^{E}\right)$ represents the excess free energy due to short range interaction between dissimilar molecules. The above terms are given in detail in (2):

$$
\begin{aligned}
\Delta F^{E}=-\left[\frac{N_{A}}{2}\right]\left\{\left[\sum_{r=1,2} \phi_{r}^{2} \mu_{r}^{2}\left(R_{f r}-R_{f r}^{0}\right)\right]\right. \\
+\left[\sum_{r=1,2} \phi_{r}^{2} \mu_{r}^{2}\left(g_{r r}-1\right)\right. \\
\left.\quad \times\left(R_{f r}-R_{f r}^{0}\right)\right] \\
+\left[\phi_{1} \phi_{2} \mu_{1} \mu_{2}\left(g_{12}-1\right)\right. \\
\left.\left.\times\left(R_{f 1}+R_{f 2}-R_{f 1}^{0}-R_{f 2}^{0}\right)\right]\right\},
\end{aligned}
$$


TABLE 3: Values of excess Helmholtz free energy of mixing for anilines + 2-butoxyethanol binary mixtures at 298.15 K.

\begin{tabular}{|c|c|c|c|c|}
\hline$\phi_{2}$ & $\begin{array}{l}\Delta F_{0 r}^{E} \\
\mathrm{~J} / \mathrm{mol}\end{array}$ & $\begin{array}{l}\Delta F_{r r}^{E} \\
\mathrm{~J} / \mathrm{mol}\end{array}$ & $\begin{array}{l}\Delta F_{12}^{E} \\
\mathrm{~J} / \mathrm{mol}\end{array}$ & $\begin{array}{c}\Delta F^{E} \\
\mathrm{~J} / \mathrm{mol}\end{array}$ \\
\hline \multicolumn{5}{|c|}{ Aniline +2 -butoxyethanol } \\
\hline 0 & 0.000 & 0.000 & 0.000 & 0.000 \\
\hline 0.25 & 12.667 & 1.195 & -24.375 & -10.513 \\
\hline 0.5 & -12.462 & 3.531 & -9.455 & -18.385 \\
\hline 0.75 & -35.202 & 4.514 & -0.070 & -30.758 \\
\hline 1 & 0.000 & 0.000 & 0.000 & 0.000 \\
\hline \multicolumn{5}{|c|}{$o$-Chloroaniline +2 -butoxyethanol } \\
\hline 0 & 0.000 & 0.000 & 0.000 & 0.000 \\
\hline 0.25 & 5.315 & 2.646 & -8.528 & -0.567 \\
\hline 0.50 & -17.290 & 7.956 & -3.584 & -12.918 \\
\hline 0.75 & -17.337 & 6.199 & -0.525 & -11.663 \\
\hline 1 & 0.000 & 0.000 & 0.000 & 0.000 \\
\hline \multicolumn{5}{|c|}{$m$-Chloroaniline +2 -butoxyethanol } \\
\hline 0 & 0.000 & 0.000 & 0.000 & 0.000 \\
\hline 0.25 & 8.096 & -7.248 & 5.254 & 6.102 \\
\hline 0.5 & 44.607 & -20.755 & -2.314 & 21.538 \\
\hline 0.75 & 56.248 & -22.579 & 0.869 & 34.538 \\
\hline 1 & 0.000 & 0.000 & 0.000 & 0.000 \\
\hline \multicolumn{5}{|c|}{$o$-Anisidine +2 -butoxyethanol } \\
\hline 0 & 0.000 & 0.000 & 0.000 & 0.000 \\
\hline 0.25 & -7.335 & 10.956 & -43.957 & -40.336 \\
\hline 0.5 & -54.914 & 36.394 & -26.484 & -45.004 \\
\hline 0.75 & -82.072 & 43.962 & 0.696 & -37.414 \\
\hline 1 & 0.000 & 0.000 & 0.000 & 0.000 \\
\hline \multicolumn{5}{|c|}{$m$-Anisidine +2 -butoxyethanol } \\
\hline 0 & 0.000 & 0.000 & 0.000 & 0.000 \\
\hline 0.25 & 3.515 & -0.395 & -2.680 & 0.440 \\
\hline 0.5 & -0.741 & -1.016 & -0.980 & -2.737 \\
\hline 0.75 & -3.759 & -0.971 & 0.646 & -4.085 \\
\hline 1 & 0.000 & 0.000 & 0.000 & 0.000 \\
\hline
\end{tabular}

$$
\begin{aligned}
& R_{f r}^{0}=\left(\frac{8 \pi N_{A}}{9 V_{r}}\right) \frac{\left(\varepsilon_{r}-1\right)\left(\varepsilon_{\mathrm{o} r}+2\right)}{\left(2 \varepsilon_{r}+\varepsilon_{\mathrm{\infty} r}\right)}, \\
& R_{f r}=\left(\frac{8 \pi N_{A}}{9 V_{r}}\right) \frac{\left(\varepsilon_{m}-1\right)\left(\varepsilon_{\mathrm{c} r}+2\right)}{\left(2 \varepsilon_{m}+\varepsilon_{\mathrm{o} r}\right)} .
\end{aligned}
$$

In the case of aniline, $o$-chloroaniline, $o$-anisidine, and $m$-anisidine with 2-butoxyethanol systems the values of $\left(\Delta F_{0 r}^{E}\right)$ are positive and less negative for $o$-anisidine +2 butoxyethanol at lower concentrations of anilines and negative at higher concentrations of anilines. It means that at initial concentration of anilines there is the existence of attractive force between the dipoles, while at higher concentrations of anilines there exists repulsive force between the dipoles. In the case of $m$-chloroaniline 2-butoxyethanol system the $\left(\Delta F_{0 r}^{E}\right)$ values are positive for the whole composition range. This shows the existence of attractive force between the dipoles. The $\left(\Delta F_{r r}^{E}\right)$ predicts the information of the short range interaction and self-association between like molecules. Increase of $\left(\Delta F_{r r}^{E}\right)$ with volume fraction of the aniline molecules suggests that the strength of the homointeraction between aniline molecules increases. The maximum values of $\left(\Delta F_{r r}^{E}\right)$ for the studied systems indicate the strong short range interaction through hydrogen bonding. In our systems, $O$-anisidine with 2-butoxyethanol has the maximum value of $\left(\Delta F_{r r}^{E}\right)$.

The magnitude of $\left(\Delta F_{12}^{E}\right)$ gives information on the strength of interactions between unlike molecules. According to Swain and Roy [36] antiparallel alignment leads to the destruction of angular correlation between dissimilar molecules decreasing internal energy and results in the increase of $\left(\Delta F_{12}^{E}\right)$ values. The $\left(\Delta F_{12}^{E}\right)$ values, aniline, and $o$-chloroaniline with 2-butoxyethanol systems are completely negative. In the case of $o$-anisidine +2 -butoxyethanol 
TABLE 4: Values of adjustable parameters $\left(B_{k}\right)$ and the corresponding standard deviations $(\sigma)$, for excess dielectric constant and excess inverse relaxation time of anilines +2 -butoxyethanol binary mixtures at $298.15 \mathrm{~K}$.

\begin{tabular}{|c|c|c|c|c|c|c|c|c|}
\hline & & & & able para & & & $\sigma$ & \% Error \\
\hline & & $B_{0}$ & $B_{1}$ & $B_{2}$ & $B_{3}$ & $B_{4}$ & $\sigma$ & / 0 LIIU⿴囗十⺝ \\
\hline Aniline & $\varepsilon^{E}$ & 0.026 & -0.629 & -0.314 & 0.629 & 0.288 & $2.47 \times 10^{-05}$ & 0.008 \\
\hline & $(1 / \tau)^{E}$ & -0.045 & 0.020 & -0.024 & -0.020 & 0.069 & $1.14 \times 10^{-05}$ & 0.004 \\
\hline$o-\mathrm{CA}$ & $\varepsilon^{E}$ & 0.388 & 1.301 & -4.158 & -1.301 & 3.770 & $2.10 \times 10^{-05}$ & 0.005 \\
\hline On & $(1 / \tau)^{E}$ & -0.017 & 0.006 & 0.002 & -0.006 & 0.014 & $3.66 \times 10^{-05}$ & 0.009 \\
\hline$m-\mathrm{CA}$ & $\varepsilon^{E}$ & -1.660 & -0.391 & 0.620 & 0.391 & 1.040 & $4.94 \times 10^{-06}$ & 0.001 \\
\hline$m-m_{n}$ & $(1 / \tau)^{E}$ & 0.001 & 0.000 & 0.000 & 0.000 & 0.000 & $4.67 \times 10^{-08}$ & 0.006 \\
\hline$o-\mathrm{A}$ & $\varepsilon^{E}$ & 3.200 & 4.693 & -3.626 & -4.693 & 0.426 & $2.10 \times 10^{-05}$ & 0.008 \\
\hline$U=\Lambda$ & $(1 / \tau)^{E}$ & -0.094 & 0.084 & -0.080 & -0.084 & 0.175 & $1.12 \times 10^{-04}$ & 0.007 \\
\hline$m$ & $\varepsilon^{E}$ & -0.120 & 0.213 & -0.253 & -0.213 & 0.373 & $1.66 \times 10^{-05}$ & 0.002 \\
\hline & $(1 / \tau)^{E}$ & -0.013 & -0.004 & 0.016 & 0.004 & -0.003 & $3.22 \times 10^{-05}$ & 0.005 \\
\hline
\end{tabular}

and $m$-anisidine +2 -butoxyethanol systems the $\left(\Delta F_{12}^{E}\right)$ values are initially negative and the volume fraction of aniline that increases the $\left(\Delta F_{12}^{E}\right)$ values goes to positive. It indicates that the dipoles have parallel orientation in 2alkoxyethanol rich region and the dipoles have antiparallel orientation in anilines rich region, where as in the case of $m$-chloroaniline +2 -butoxyethanol system the $\left(\Delta F_{12}^{E}\right)$ values are positive for $m$-chloroaniline and 2-butoxyethanol rich region and negative for equimolar ratio. This shows that the conversion of multimers leads to the internal energy. The $\left(\Delta F_{12}^{E}\right)$ values are very small at all concentrations. This shows that interaction does not result in a structure breaking mechanism between dissimilar molecules. Hence it may be concluded that hydrogen bonds between the dissimilar molecules are not broken by change in the composition of the mixture.

Finally the total excess Helmholtz free energy $\left(\Delta F^{E}\right)$ values are negative for aniline, $o$-chloroaniline, $o$-anisidine, and $m$-anisidine and positive for $m$-chloroaniline systems. The negative values of $\left(\Delta F^{E}\right)$ indicate the formation of $\alpha$ clusters. Due to the formation of these $\alpha$-clusters the effective dipole moment will be increased which increases the internal energy. The positive values of $\left(\Delta F^{E}\right)$ are due to the formation of $\beta$-clusters and hence the effective dipole moment will be decreased when compared to the sum of individual systems and thereby it destructs the angular correlation between nonideal molecules which may decrease its internal energy. Hence the dipolar excess free energy or excess Helmholtz free energy can be considered to be a reflection of the interaction between the islands of anilines in 2-alkoxyethanols (Figure 4). The excess values are fitted with Redlich-Kister [37] polynomial equation and the average standard deviation values are calculated. These values are listed in Table 4 . The derived dielectric parameters and excess functions from the measured properties suggest the presence of strong molecular interactions in the solution to obtain binary coefficients and the standard errors in the Redlich-Kister polynomial equation at $298.15 \mathrm{~K}$ as a function of composition of the mixture.

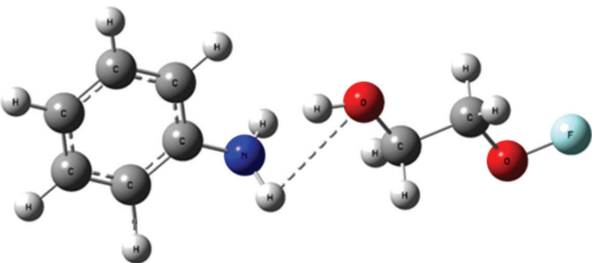

(a)

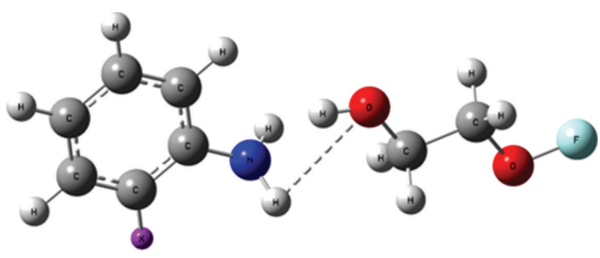

$\mathrm{F}=\mathrm{CH}_{3} \mathrm{CH}_{2} \mathrm{CH}_{2} \mathrm{CH}_{2}$

(b)

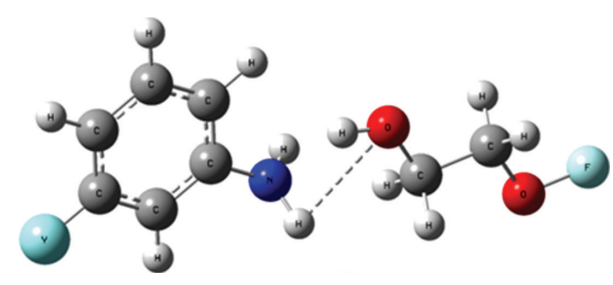

$\mathrm{X}, \mathrm{Y}=\mathrm{Cl}, \mathrm{OCH}_{3}$

(c)

FIGURE 4: Interaction behaviour of anilines + 2-butoxyethanol.

\section{Conclusion}

The complex permittivity spectra of 2-butoxyethanol in anilines have been studied using time domain reflectometry technique in the frequency range $10 \mathrm{MHz}$ to $30 \mathrm{GHz}$. A nonlinear variation of static dielectric constant and relaxation time values suggests the heterogeneous interaction between 
the unlike molecules. The calculated values like Kirkwood correlation factors, Bruggeman factor, and excess dielectric constant values confirm the hydrogen bond interaction between 2-BE with anilines. The negative total excess free energies $\Delta F^{E}$ may be attributed to the $\mathrm{H}$-bonding interaction between unlike molecules over the depolymerization of 2-BE by anilines.

\section{Conflict of Interests}

The authors declare that there is no conflict of interests regarding the publication of this paper.

\section{Acknowledgment}

The authors gratefully acknowledged the School of Physical Science, S.R.T.M University, Nanded, Maharashtra, for providing the TDR measurements.

\section{References}

[1] D. Balamurugan, S. Kumar, and S. Krishnan, "Dielectric relaxation studies of higher order alcohol complexes with amines using time domain reflectometry," Journal of Molecular Liquids, vol. 122, no. 1-3, pp. 11-14, 2005.

[2] P. Sivagurunathan, K. Dharmalingam, K. Ramachandran, B. Prabhakar Undre, P. W. Khirade, and S. C. Mehrotra, "Dielectric relaxation study of ethyl acrylate-alcohol mixtures using time domain Reflectometry," Lithanian Journal of Physics, vol. 46, no. 4, pp. 441-445, 2006.

[3] Y. S. Joshi and A. C. Kumbharkhane, "Study of heterogeneous interaction in binary mixtures of 2-methoxyethanol-water using dielectric relaxation spectroscopy," Journal of Molecular Liquids, vol. 161, no. 3, pp. 120-124, 2011.

[4] V. A. Rana, A. D. Vyas, and S. C. Mehrotra, "Dielectric relaxation study of mixtures of 1-propanol with aniline, 2chloroaniline and 3-chloroaniline at different temperatures using time domain reflectometry," Journal of Molecular Liquids, vol. 102, no. 1-3, pp. 379-391, 2003.

[5] T. V. Krishna and S. S. Sastry, "Dielectric and thermodynamic studies on the hydrogen bonded binary system of isopropyl alcohol and aniline," Journal of Solution Chemistry, vol. 39, no. 9, pp. 1377-1393, 2010.

[6] T. Kalaivani and S. Krishnan, "Dielectric relaxation studies of ternary liquid mixtures of aniline and substituted anilines with acrylonitrile in the microwave region," Indian Journal of Pure and Applied Physics, vol. 47, no. 12, pp. 880-882, 2009.

[7] R. J. Sengwa, V. Khatri, and S. Sankhla, "Dielectric properties and hydrogen bonding interaction behaviour in binary mixtures of glycerol with amides and amines," Fluid Phase Equilibria, vol. 266, no. 1-2, pp. 54-58, 2008.

[8] A. N. Prajapati, V. A. Rana, and A. D. Vyas, "Dielectric dispersion studies of mixtures of aniline and benzonitrile in benzene solutions," Journal of Molecular Liquids, vol. 144, no. 1-2, pp. 1-4, 2009.

[9] K. K. Gupta, A. K. Bansal, P. J. Singh, and K. S. Sharma, "Structural change analysis of pyridine and piperidine through dielectric relaxation studies," Journal of Molecular Liquids, vol. 108, no. 1-3, pp. 79-93, 2003.
[10] U. Becker and M. Stockhausen, "A dielectric relaxation study of some mixtures of mono and dihydric alcohols," Journal of Molecular Liquids, vol. 81, no. 2, pp. 89-100, 1999.

[11] A. C. Kumbharkhane, S. M. Puranik, and S. C. Mehrotra, "Dielectric relaxation study and structural properties of 2nitroacetophenone-ethanol solutions from $10 \mathrm{MHz}$ to $10 \mathrm{GHz}$," Journal of Molecular Liquids, vol. 51, no. 3-4, pp. 307-319, 1992.

[12] S. M. Puranik, A. C. Kumbharkhane, and S. C. Mehrotra, "Dielectric relaxation studies of aqueous $\mathrm{N}, \mathrm{N}$ dimethylformamide using a picosecond time domain technique," Journal of Solution Chemistry, vol. 22, no. 3, pp. 219-229, 1993.

[13] Y. S. Joshi, P. G. Hudge, A. C. Kumbharkhane, and S. C. Mehrotra, "The dielectric relaxation study of 2(2alkoxyethoxy)ethanol-water mixtures using time domain reflectometry," Journal of Molecular Liquids, vol. 163, no. 2, pp. 70-76, 2011.

[14] P. R. Bevington, Data Reduction and Error Analysis for the Physical Sciences, McGraw Hill, New York, NY, USA, 1969.

[15] A. Chaudhari, N. M. More, and S. C. Mehrotra, "Static dielectric constant and relaxation time for the binary mixture of water, ethanol, N,N-dimethylformamide, dimethylsulphoxide, and N,N-dimethylacetamide with 2-methoxyethanol," Bulletin of the Korean Chemical Society, vol. 22, no. 4, pp. 357-361, 2001.

[16] A. C. Kumbharkhane, S. N. Helambe, S. Doraiswamy, and S. C. Mehrotra, "Dielectric relaxation study of hexamethylphosphoramide-water mixtures using time domain reflectometry," The Journal of Chemical Physics, vol. 99, no. 4, pp. 2405-2409, 1993.

[17] B. D. Achole, A. V. Patil, V. P. Pawar, and S. C. Mehrotra, "Study of interaction through dielectrics: behavior of $-\mathrm{OH}$ group molecules from $10 \mathrm{MHz}$ to $20 \mathrm{GHz}$," Journal of Molecular Liquids, vol. 159, no. 2, pp. 152-156, 2011.

[18] L. S. Gabrielyan and S. A. Markarian, "Dielectric relaxation study of dipropylsulfoxide/water mixtures," Journal of Molecular Liquids, vol. 162, no. 3, pp. 135-140, 2011.

[19] Y. S. Joshi, P. G. Hudge, and A. C. Kumbharkhane, "Dielectric relaxation study of aqueous 2-ethoxyethanol using time domain reflectometry technique," Indian Journal of Physics, vol. 85, no. 11, pp. 1603-1614, 2011.

[20] K. K. Srivastava and J. K. Vij, "Dielectric relaxation and molecular structure. I. Dielectric relaxation in substituted anilines," Bulletin of Chemical Society of Japan, vol. 43, pp. 2307-2312, 1970.

[21] J. G. Kirkwood, "The dielectric polarization of polar liquids," The Journal of Chemical Physics, vol. 7, no. 10, pp. 911-919, 1939.

[22] S. B. Sayyad, P. B. Undre, P. Yannewar, S. S. Patil, P. W. Khirade, and S. C. Mehrotra, "Investigations of intermolecular interactions between 2-methoxyethanol and nitrobenzene through dielectric relaxation study," Lithuanian Journal of Physics, vol. 51, no. 1, pp. 29-37, 2011.

[23] D. A. G. Bruggeman, "The dielectric constant of a composite material," Annals of Physics, vol. 5, p. 636, 1935.

[24] J. B. Hasted, Aqueous Dielectrics, Champan and Hall, London, UK, 1973.

[25] V. P. Pawar and S. C. Mehrotra, "Dielectric relaxation study of chlorobenzene with formamide at microwave frequency using time domain reflectometry," Journal of Molecular Liquids, vol. 115, no. 1, pp. 17-22, 2004.

[26] P. Undre, S. N. Helambe, S. B. Jagdale, P. W. Khirade, and S. C. Mehrotra, "Microwave dielectric characterization of binary 
mixture of formamide with N, N-dimethylaminoethanol," Pramana, vol. 68, no. 5, pp. 851-861, 2007.

[27] D. A. G. Bruggeman, "The dielectric constant of a composite material-a problem in classical physics," Annals of Physics, vol. 24, p. 636, 1967.

[28] A. Chaudhari, S. Ahire, M. Lokhande, and S. C. Mehrotra, "Dielectric study of pyridine- alcohol binary liquids at $25^{\circ} \mathrm{C}$," Proceedings of the National Academy of Sciences India Section A, vol. 1, pp. 75-83, 2001.

[29] A. Chaudhari, C. S. Patil, A. G. Shankarwar, B. R. Arbad, and S. C. Mehrotra, "Temperature dependent dielectric relaxation study of aniline in dimethylsulphoxide and dimethylformamide using time domain technique," Journal of Korean Chemical Society, vol. 45, pp. 201-206, 2001.

[30] S. C. Mehrotra and J. E. Boggs, "A new approach to timedependent perturbation theory," The Journal of Chemical Physics, vol. 64, no. 7, pp. 2796-2803, 1976.

[31] T. V. Krishna and T. MadhuMohan, "Study of molecular interactions in the polar binary mixtures of N-methyl aniline and alcohols, using excess dielectric and thermodynamic parameters," Journal of Chemical Thermodynamics, vol. 47, pp. 267-275, 2012.

[32] T. M. Mohan, S. S. Sastry, and V. R. K. Murthy, "Thermodynamic, dielectric and conformational studies on hydrogen bonded binary mixtures of propan-1-ol with methyl benzoate and ethyl benzoate," Journal of Solution Chemistry, vol. 40, no. 1, pp. 131-146, 2011.

[33] T. Thenappan and U. Sankar, "Study of correlation factors and dipolar excess free energies of esters in benzene," Journal of Molecular Liquids, vol. 126, no. 1-3, pp. 23-28, 2006.

[34] G. Arivazhagan, G. Parthipan, and T. Thenappan, "Solutesolvent interactions of acid-1,4-dioxane mixtures-By dielectric, FTIR, UV-vis and 13C NMR spectrometric methods," Spectrochimica Acta A, vol. 74, no. 4, pp. 860-868, 2009.

[35] G. Parthipan and T. Thenappan, "Dielectric and thermodynamic behavior of binary mixture of anisole with morpholine and aniline at different temperatures," Journal of Molecular Liquids, vol. 138, no. 1-3, pp. 20-25, 2008.

[36] B. B. Swain and G. S. Roy, "Dielectric studies of binary mixtures of butanols in nonpolar solvents-solute-solvent interactions," Journal of Molecular Liquids, vol. 34, no. 4, pp. 257-268, 1987.

[37] O. Redlich and A. T. Kister, "Algebraic representation of thermodynamic properties and the classification of solutions," Industrial and Engineering Chemistry, vol. 40, no. 2, pp. 345348, 1948. 

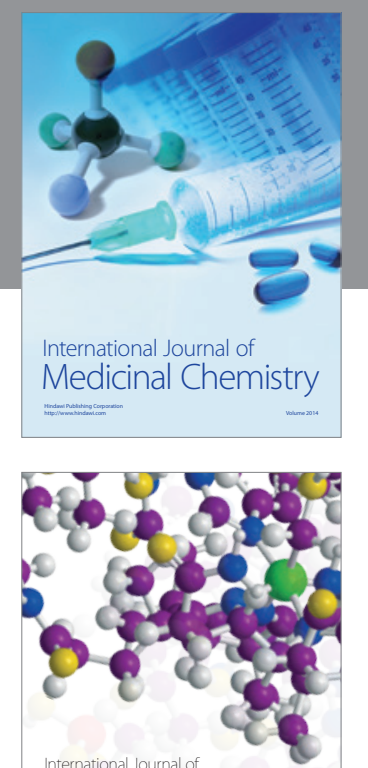

\section{Carbohydrate} Chemistry

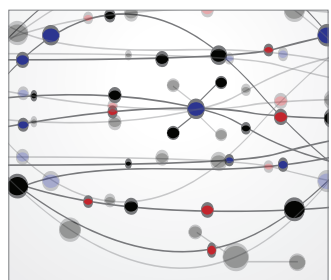

The Scientific World Journal
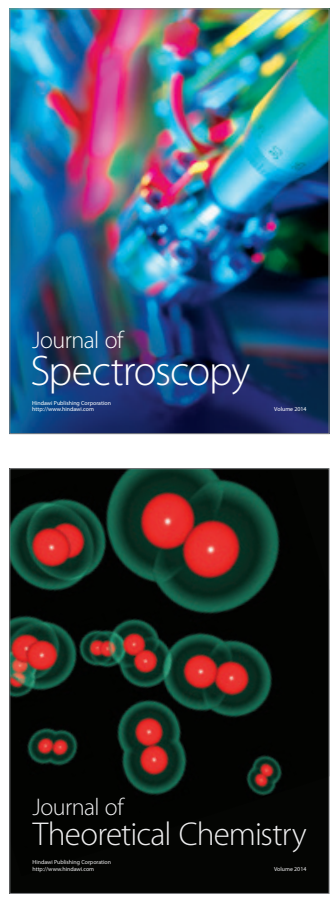
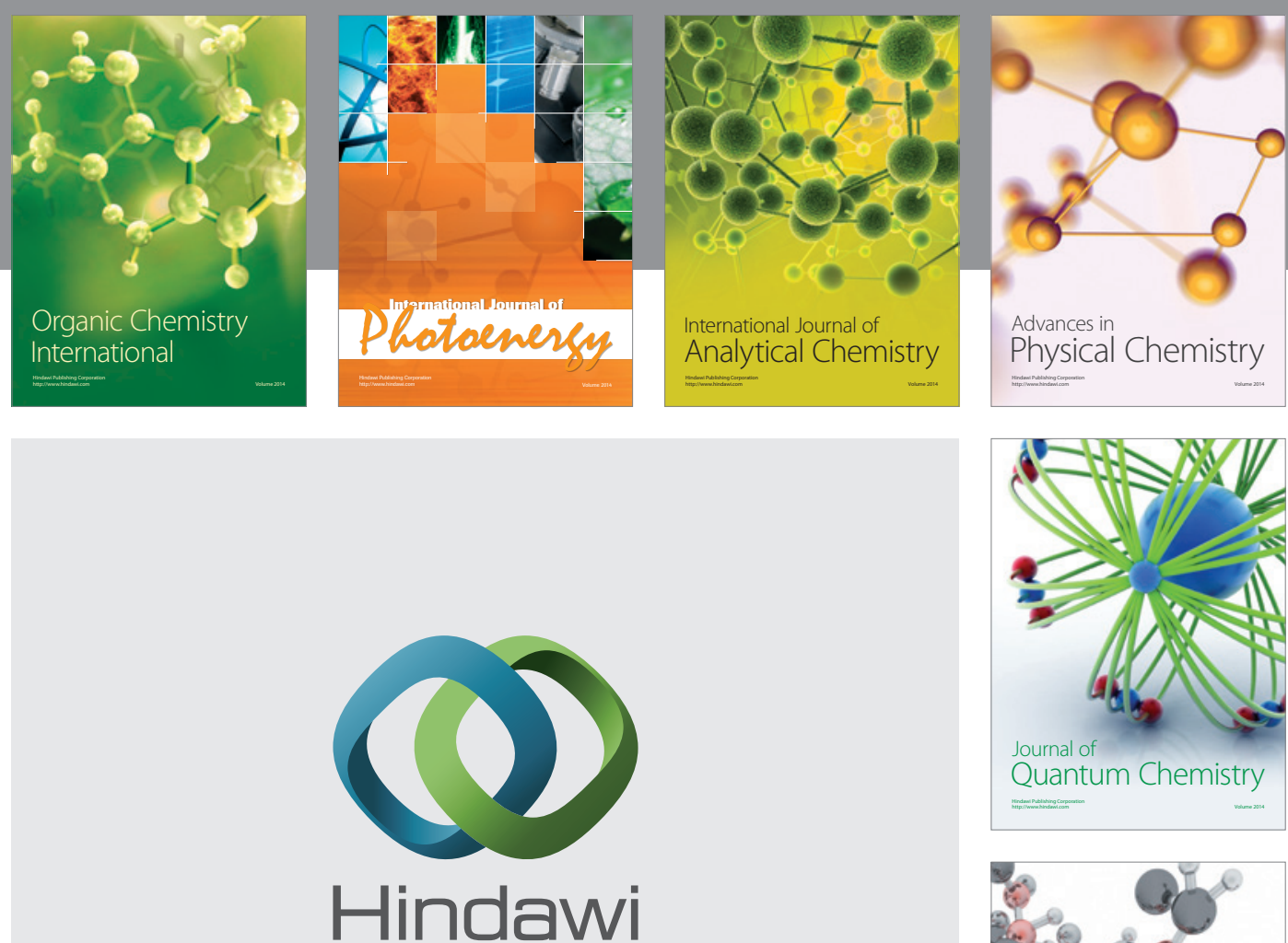

Submit your manuscripts at

http://www.hindawi.com

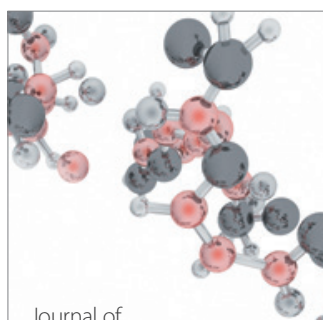

Analytical Methods

in Chemistry

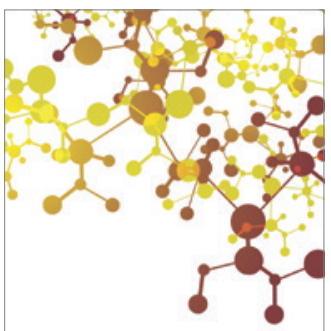

Journal of

Applied Chemistry

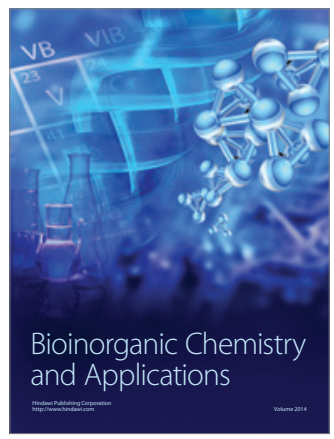

Inorganic Chemistry
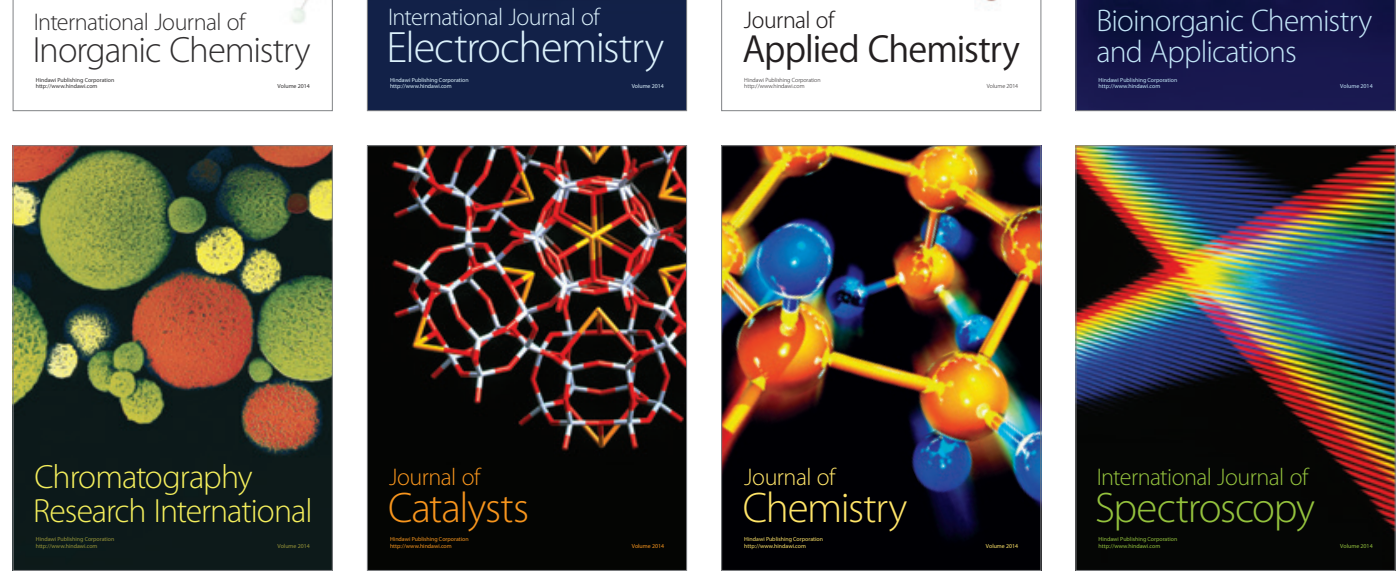